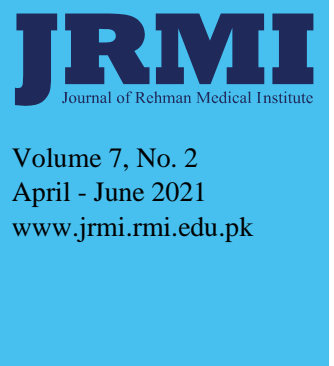

Submitted:

February 10, 2021

Accepted:

April 05, 2021

\section{Author Information}

\section{Ms. Adeela Asad}

Lecturer, Department of Physical Therapy, Rawal College of Physical Therapy, Rawal Institute of Health

Sciences, Islamabad, Pakistan (Corresponding Author)

Email:

adeelaasadfmdc@gmail.com

From: Department of Physical Therapy, Isra Institute of Rehabilitation Sciences, Isra University, Islamabad, Pakistan

\section{Ms. Noureen Farooq}

Assistant Professor

Ms. Sarah Kafeel

Assistant Professor

\section{Mr. Taimoor Hassan}

Research Associate

Mr. Muhammad Zubair Physiotherapist, Sedum School for Special Child Rawalpindi, Punjab, Pakistan

Citation: Asad A, Farooq N, Kafeel S, Hassan T, Zubair M. Association of upper crossed syndrome and posture among general population having neck pain in Islamabad. J Rehman Med Inst. 2021 Apr-Jun;7(2):7-11.

\title{
Association of upper crossed syndrome and posture among general population having neck pain in Islamabad
}

\section{Adeela Asad, Noureen Farooq, Sarah Kafeel, Taimoor Hassan, Muhammad Zubair}

\section{ABSTRACT}

Introduction: Upper crossed syndrome is a common postural dysfunctional pattern that describes the dysfunctional tone of the musculature of the shoulder girdle/ cervicothoracic region of the body.

Objective: To determine association of Upper Crossed Syndrome and Neck pain among general population in Islamabad.

Materials \& Methods: A cross sectional survey was conducted from December 2017 to February 2018 in Rawal General and Dental Hospital Islamabad, and National Institute of Rehabilitation Sciences Islamabad after approval of synopsis from Advanced Studies and Research Board. Convenience sampling was used to collect data from male and female participants having neck pain after obtaining informed consent. The questionnaires provided for a subjective assessment from the patient and an objective measure for the clinician. REEDCO scale was used to analyze the proper alignment of head, neck and shoulder, while wall push test was used to assess the abnormal protrusion of scapula. Data were analyzed for descriptive and inferential statistics by SPSS 20 ; continuous variables were expressed as mean $\pm \mathrm{SD}$, and categorical variables as frequency and percentage. A $\mathrm{p} \leq 0.05$ denoted significance.

Results: The occurrence of upper crossed syndrome was $24.1 \%$. Out of 340 respondents, $143(42.06 \%)$ had poor posture whereas 197 respondent $(57.94 \%)$ had good posture. There was strong association between posture and upper crossed syndrome $(\mathrm{p}<0.05)$.

Conclusion: Most patients with neck pain are exposed to the risk of adopting poor posture which can lead to Upper Crossed Syndrome in future; hence the importance of postural awareness among general population of Islamabad.

Keywords: Neck Pain; Posture; Range of Motion; Scapula Abnormalities; Shoulder Abnormalities.

The authors declared no conflict of interest. All authors contributed substantially to the planning of research, data collection, data analysis, and write-up of the article, and agreed to be accountable for all aspects of the work.

\section{INTRODUCTION}

The upper crossed syndrome is defined as weak lower and middle trapezius, short upper trapezius and Levator scapulae, weak deep neck flexors especially the scalene muscles, and short Suboccipital muscles and Sternocleidomastoid, weak Serratus anterior and short Pectoralis major and minor. ${ }^{1}$ Dr. Janda named this syndrome "Upper Crossed" because the weakened and shortened muscles are connected in the upper body to form a cross. Upper-Crossed Syndrome (UCS) is also referred to as proximal or shoulder girdle crossed syndrome. ${ }^{2}$

Sign and symptoms of UCS are rounded shoulder, forwarded head posture, elevation of shoulder, winging of scapulae, and $\mathrm{C} 0-\mathrm{C} 1$ hyperextension. These postural movements reduce glenohumeral quality as the glenoid fossa gets the opportunity to be more vertical on account of Serratus frontal weakness provoking grabbing, turn, and winging of the scapulae. $^{3}$ Differential diagnosis of UCS includes Upper Thoracic Outlet Syndrome, stress and anxiety, Pseudo Radicular syndrome (blockage of C5/6, C6/7, Th1), Blockages of Acromioclavicular joint, $1^{\text {st }}$ and $2^{\text {nd }}$ ribs, and Scalene syndrome.

Specifically, the back muscles of the neck and shoulders (upper Trapezius, and Levator Scapulae) become extremely overactive and strained. The muscles in the front of the chest (the major and minor pectoralis muscles) become shortened and tight. $^{4}$

In this postural disorder, weakened muscles include the Rhomboids, Serratus Anterior, middle and lower Trapezius; some tightened / overactive muscles include upper Trapezius, Pectoralis Major, and Levator Scapulae in this posture leading to postural abnormalities (e.g. Head and shoulder shifted anteriorly). ${ }^{3,5}$ In other words, this posture creates postural patterning of forward shoulders, increases kyphosis, forward head posture, and increases cervical lordosis. These abnormalities lead to overall pattern changes in the upper quarter of the body. ${ }^{3}$ These pattern changes can cause strain to the muscular attachments of the shoulder and shoulder blades which produce a rounded shoulder appearance. ${ }^{6}$ Although this posture does not necessarily lead to pain, but when prolonged, individuals do often experience upper back and neck pain. 
As our employees continue to evolve, the usage of laptop terminals and automated devices emphasis workers to preserve a seated posture for a protracted period of time. "In response to ache, overuse, joint dysfunction or proprioceptive adjustments muscle mass reaction by using either becoming short and tight or susceptible and inhibited. These responses do now not occur at random, but incredibly in traditional fashion. The postural muscle groups probably to end up tight whereas the phasic muscle tissue generally tends to expand weakness and inhibition. Therefore, once muscle disorder begins, traditional styles of muscle imbalance and adjusted posture turn up". 7 The seated posture is a flexor-subjected posture that moreover shortens and tightens the muscles on the ventral facet of the body and lengthens whilst weakening the muscles on the dorsal aspect of the frame. "Because of the muscle imbalances that develop in our musculoskeletal device, postural distortions occur that tend to correspond with the muscular findings". 8

Posture is a result of several biomechanical processes within the body to include but not limited to, joint structure and function, muscle balance, nervous system function, and the righting reflex. Through the aging process, UCS affects one's ability to compensate for unusual functioning systems within our bodies. This decrease in compensation and increase in related symptoms can lead to more chronic and degenerative changes. ${ }^{9}$

"As we grow older, our posture tends to decline; not only do the shoulders become more rounded, but the head becomes protracted forward and the thoracic spine (or upper back), more curved. In time, faulty alignment and poor posture can add abnormal stress to tissues, leading to degenerative joint changes and pain. Bad posture has also been linked to poor balance, as well as to decreases in gait and functional performance. In fact, research shows that poor posture is even associated with increased mortality rates in older adults". ${ }^{10}$ "Typically, muscles overused in a certain direction will become tighter and shorteran effect known as adaptive shortening. Opposing muscles to repetitive movements sustain stretches during prolonged postures. As a result, these muscles will tend to become longer and weaker-an effect known as stretch weakness". ${ }^{11}$

The present study was conducted to find out the postural alteration in general population of Islamabad having neck pain and Upper Crossed Syndrome.

\section{MATERIALS \& METHODS}

A cross sectional survey was conducted at Rawal General and Dental hospital Islamabad and National Institute of Rehabilitation Sciences Islamabad in 3 months after approval of synopsis from advanced research committee from December 2017 to February 2018.

Participants with age of 18 years and above, poor posture and who had a medical history consistent with the diagnosis of neck pain were included in study, while participants with spinal trauma, joint dysfunction, congenital defects, pain due to any systemic inflammatory diseases and those with acute spasm of paraspinal muscles of neck/cervical region or sprain of any paravertebral structure like ligaments or fascia were excluded from the study.
After taking consent from the subjects, procedure was explained to them. The subjects were asked to assume the testing position and different tests for checking the muscle tightness and muscle strength of the required muscles were performed.

Population was estimated as 20,000 with confidence interval $95 \%$ and level of significance 5\%. The sample size was $377 ; 340$ respondents participated in the study while 37 did not participate. Non-Probability Convenience sampling was used to collect data from both male and female participants.

The Questionnaires provided a subjective assessment from patients and an objective measure for the clinician. Data were collected for demographics, Neck pain disability index Questionnaire (NPDI-1 pain intensity), and Janda's cervical flexion test.

Data collected on the basis of these tests were analyzed by SPSS 20. Quantitative variables were analyzed for mean and standard deviation while Qualitative variables were analyzed for frequencies and percentages. Chi-square test was performed to check the association between neck pain and upper crossed syndrome; $\mathrm{p} \leq 0.05$ denoted significance.

\section{REEDCO SCALE}

Proper position of head, neck, upper back, shoulder and spine were analyzed by using REEDCO scale. REEDCO posture assessment scale was used to assess obtained scores according to posture score sheet. The scale comprised three grades 10,5 and 0 namely good, fair and poor respectively.

\begin{tabular}{l|l|l} 
Grade 0 - poor & Grade 5 - fair & Grade 10 - good \\
\hline
\end{tabular}

\section{JANDA'S CERVICAL FLEXION TEST}

Evaluation of the deep cervical muscles was done by using Janda's Cervical Flexion Test. Patient was made to lie in supine position and then asked to lift the head from the couch; the smoothness of the movement was observed. Normally lordosis will disappear and the chin will touch the sternum. Otherwise pathological picture shows that the head is lifted with very tense sternocleidomastoids. $^{12}$

\section{RESULTS}

Demographic data of subjects are given in Table 1.

The mean age of respondents was $32.41 \pm 11.72$ years (ranging from 18 years to 72 years). The mean height of respondents was $65.30 \pm 41.06$ inches (ranging from 30 inches to 75 inches). The mean weight of respondents was $64.65 \pm 12.56 \mathrm{~kg}$, (ranging from $29 \mathrm{~kg}$ to $140 \mathrm{~kg}$ ). The mean number of sitting hours were 08.30 \pm 03.07 hours (ranging from 2 hours to 16 hours).

Table 1: Demographic data of subjects $(n=340)$.

\begin{tabular}{|l|c|c|}
\hline \multicolumn{1}{|c}{ Variables } & Mean & \multicolumn{1}{c|}{ SD } \\
\hline Age & 32.41 & 11.72 \\
\hline Height (inches) & 65.30 & 41.06 \\
\hline Weight $(\mathrm{kg})$ & 64.65 & 12.56 \\
\hline BMI & 24.34 & 04.99 \\
\hline No. of sitting hours & 08.30 & 03.07 \\
\hline
\end{tabular}


Postural Scoring of different areas by REEDCO scale is shown in Figures 1-6.

Figure 1 shows that for Head score, out of 340 respondents, 40 $(11.8 \%)$ were in grade $0,197(57.9 \%)$ were in grade 5 , and 102 $(30.3 \%)$ were in grade 10.

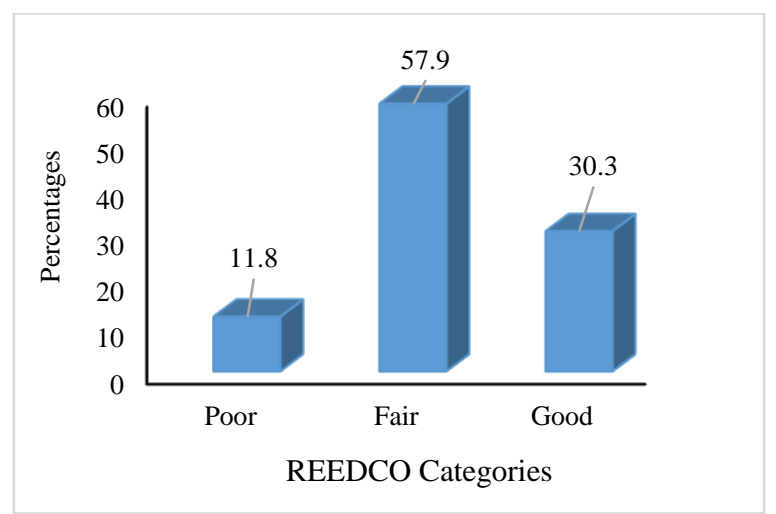

Figure 1: Postural scoring of Head by REEDCO scale.

Figure 2 shows that, out of 340 respondents, 39 (11.5\%) respondents were in grade 0 having poor Shoulder posture, 209 $(61.5 \%)$ respondents were in grade 5 having fair shoulder posture, and $92(27.1 \%)$ respondents were in grade 10 having good shoulder posture.

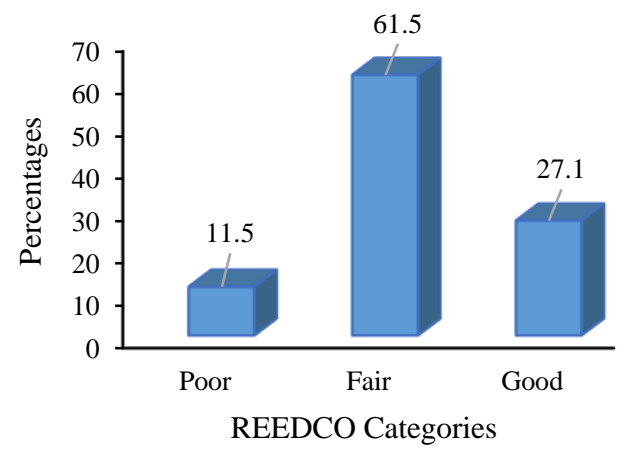

Figure 2: Postural scoring of Shoulder by REEDCO Scale.

Figure 3 shows the grading of Spine posture; out of 340 respondent, 22 (6.5\%) population were in grade 0 (poor), 149 $(43.8 \%)$ were in grade 5 (fair), and $169(49.7 \%)$ population were in grade 10 (good).

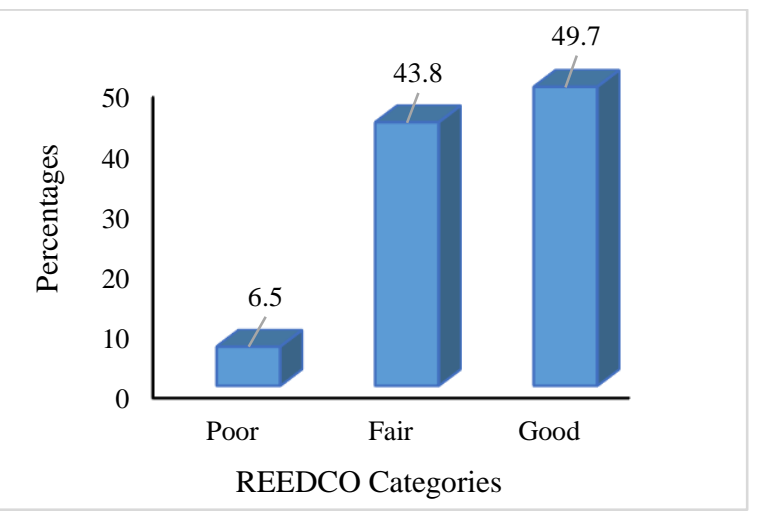

Figure 3: Postural scoring of Spine by REEDCO Scale.
Figure 4 shows Neck posturing; out of 340 respondents, 69 $(20.3 \%)$ were in grade 0 (poor), $201(59.1 \%)$ were in grade 5 (fair) and $70(20.6 \%)$ were in grade 10 (good).

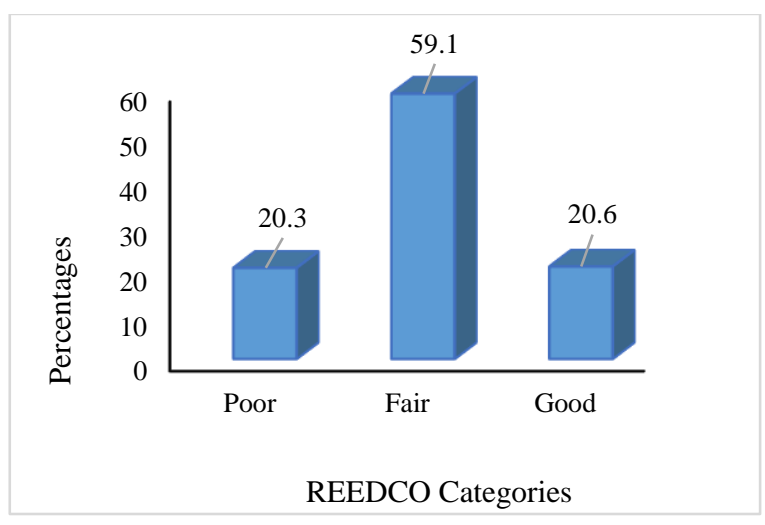

Figure 4: Postural scoring of Neck by REEDCO Scale.

Figure 5 shows the scoring for Upper Back; out of 340 respondents it was found that $76(22.4 \%)$ was in grade 0 (poor); $190(55.9 \%)$ respondents in grade 5 (fair), and $74(21.8 \%)$ in grade 10 (good).

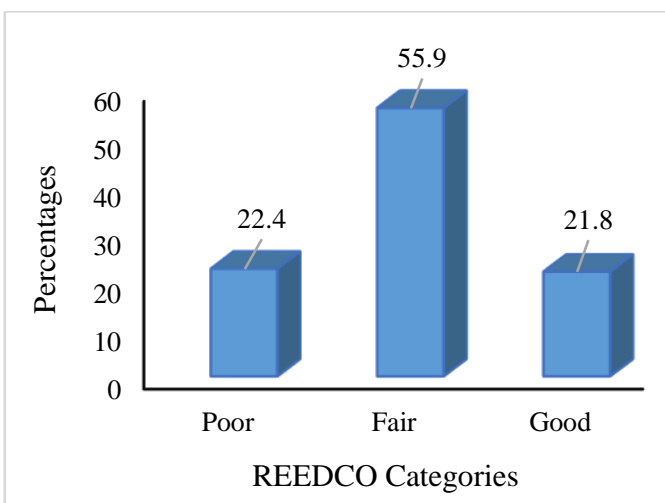

Figure 5: Postural scoring of upper back by REEDCO Scale.

Figure 6 shows the Overall REEDCO scores of 340 respondents; $143(42.06 \%)$ had a poor posture whereas $197(57.94 \%)$ had a good posture.

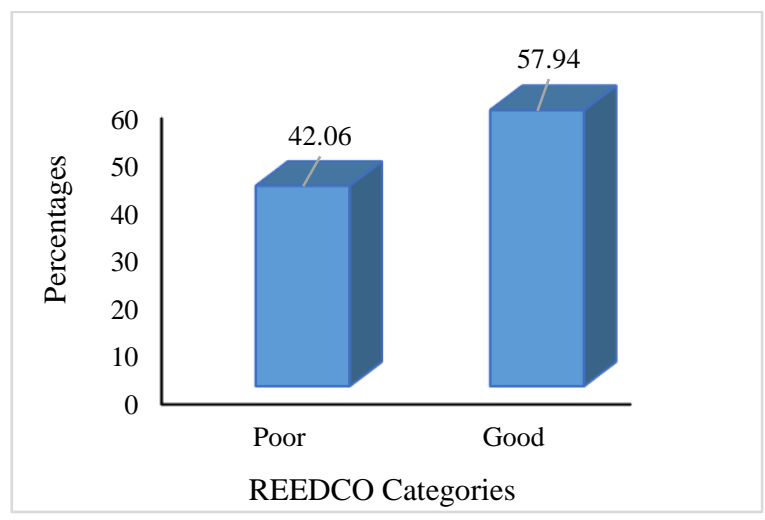

Figure 6: Overall postural scoring by REEDCO Scale.

Table 2 shows the association of postural alteration with the upper crossed syndrome by using the Chi Square test of Association. A highly significant association was observed with $\mathrm{p}<0.001$. 
Table 2: Association of Postural alteration (REEDCO scale) and Upper Crossed Syndrome $(n=340)$.

\begin{tabular}{|c|c|c|c|c|}
\hline \multirow{3}{*}{\multicolumn{2}{|c|}{$\begin{array}{l}\text { Janda's cervical } \\
\text { flexion test }\end{array}$}} & \multicolumn{2}{|c|}{ REEDCO categories } & \multirow{3}{*}{$\begin{array}{c}p- \\
\text { value }\end{array}$} \\
\hline & & \multirow{2}{*}{$\begin{array}{c}\text { Poor } \\
\text { posture } \\
(\mathrm{n}=143)\end{array}$} & \multirow{2}{*}{$\begin{array}{l}\text { Good } \\
\text { posture } \\
(\mathrm{n}=197)\end{array}$} & \\
\hline & & & & \\
\hline \multirow{2}{*}{$\begin{array}{l}\text { Test } \\
\text { Results }\end{array}$} & $\begin{array}{c}\text { Positive } \\
(\mathrm{n}=82)\end{array}$ & 82 & 0 & \multirow[t]{2}{*}{$<0.001$} \\
\hline & $\begin{array}{c}\text { Negative } \\
(\mathrm{n}=258)\end{array}$ & 61 & 197 & \\
\hline
\end{tabular}

Out of 340 respondents, 82 (24.1\%) participants diagnosed with upper crossed syndrome had poor posture, while 258 (75.9\%) respondents were not diagnosed with Upper crossed syndrome; of those testing negative, 61 (17.9\%) participants had poor posture.

Occurrence of upper crossed syndrome in the present study was $24.1 \%$.

\section{DISCUSSION}

The present study showed the occurrence of upper crossed syndrome among patients presenting to hospital with neck pain as $24.1 \%$. Furthermore, a strong association was found between posture and upper crossed syndrome $(\mathrm{p}<0.001)$. In the study out of 340 respondent, $143(42.06 \%)$ population had a poor posture whereas 197 (57.94\%) population had a good posture.

In 2016, research was conducted on topic "Prevalence of upper crossed syndrome among the medical students of university of Lahore". In this study relation between Upper Crossed Syndrome and posture were seen. It was concluded that bad posture causes muscle imbalance and yield Upper Crossed Syndrome. Prevalence of upper crossed syndrome in medical students of University of Lahore was found to be $37.1 \% .^{13}$

In the present study, $11.5 \%$ had rounded shoulders, $6.5 \%$ had increased thoracic curve, and $86.8 \%$ had headache along with neck pain.

In 2011, a study conducted on the "Influence of sports on the development of postural disorders in athletes" showed that population with upper crossed syndrome not only had greater values of thoracic kyphosis $(\mathrm{p}=0.013)$ but also forward head posture $(p=0.001)$, rounded shoulder $(p=0.009)$ and uneven shoulders $(\mathrm{p}=0.001)$. It seems that kyphosis is among the most common postural abnormalities that occur in most postural abnormality, while lordosis occurs to a slightly smaller extent. ${ }^{14}$

In 2017, interventional study on "Effect of Eight-Week Selected Corrective Exercises on Upper Crossed Syndrome in Dentist" was conducted in Iran. ${ }^{15}$ Sample size of 30 dentists was taken in this experimental research. Long term inappropriate postures can cause wide negative patterns and compatibles in the joints and soft tissues. An alteration in the muscle as muscle imbalance affects the body natural alignment. Due to the placement of inappropriate situations and long working hours' dentists are exposed to disorders. The aim of this study was to evaluate the effect of 8-week period of corrective exercises on the upper crossed syndrome in dentistry. By referring to clinics and dental offices for participating in this research, a total of 30 dentists took part in this research. In general, the results showed, eight-week selected corrective exercises as a treatment modality with the work therapy can improve forward head angle, forward shoulder angle, kyphosis angle.

S Raja Rajeswari and his colleagues (2017) ${ }^{16}$ studied on "Upper Crossed Syndrome and Dentistry why The Need for Concern" in India. This studies says that Dentists are prone for improper posture and associated muscle strain. Improper body posture inherent in dentistry, paves way for increased incidence of neck pain and UCS. Numerous suggestions were put forth for altering the assumption of awkward posture, including improved equipment ergonomics, appreciative workspace up gradation, physical therapy and active life style adaptation. Early identification and prevention of UCS is crucial in preventing further degenerative changes and treating the musculoskeletal pain.

Relation between upper crossed syndrome and bad posture was seen and it was found that the individuals suffering with upper crossed syndrome were somehow related to bad posture or indulged in activities which make individual adopt a poor posture thereby leading to muscular imbalance that will yield upper cross syndrome. ${ }^{3}$

André Klussmanet at $\mathrm{al}^{17}$ in 2008 conducted study on musculoskeletal symptoms of the upper extremities and the neck a cross-sectional study on prevalence and symptom-predicting factors at visual display terminal (VDT) workstations. In this study it was found that only $33.1 \%$ population had normal studying posture, whereas $66.8 \%$ population had poor studying posture and out of which $43.1 \%$ studied while laying down on their stomach and $23.7 \%$ studied while having book in their lap with flexed back.

Posture has a direct effect on the way we look, feel, and perform, with poor posture being a leading cause of both back and neck pain. $80 \%$ of people will suffer from back pain in their lifetime and 50\% from neck pain. Bad posture is also a leading cause and main risk factor in many athletic, on-the-job, and active lifestyle injuries. Posture affects everything. With great posture, our minds and bodies get energized and flow with optimal health. With poor posture, our minds and bodies are tortured by fatigue, migraines, back pain, neck pain, depression, poor circulation/digestion, and sluggish thinking and movement. Standing with ideal posture for 30 seconds makes one feel the difference in immediately feeling more energized, confident, and positive.

\section{CONCLUSION}

A significant association between upper crossed syndrome and bad posture was documented in patients with neck pain, thereby possibly implicating upper crossed syndrome in the causation of neck pain in these patients.

\section{RECOMMENDATION}

The importance of evaluating posture with respect to upper crossed syndrome symptoms has to be emphasized in clinical care settings. 
An endurance-strength exercise regime for the cervical flexor muscles is recommended to reduce myoelectric manifestations of superficial cervical flexor muscle fatigue as well as increase cervical flexion strength in patients with chronic non-severe neck pain / upper crossed syndrome.
Future research should consider group sizes and population characteristics to achieve a validated measure for assessing posture, so that characteristics and location of cervical symptoms are clearly defined and that the upper crossed syndrome posture is sub classified.

\section{REFERENCES}

1. Tunnell PW. Muscle length assessment of tightness-prone muscles. J Bodyw Mov Ther. 1998 Jan 1;2(1):21-7.

2. Thacker D, Jameson J, Baker J, Divine J, Unfried A. Management of upper cross syndrome through the use of active release technique and prescribed exercises. [Senior Research Paper]. Logan College of Chiropractic. 2011 Apr. Available from: https://www.logan.edu/mm/files/LRC/Seni or-Research/2011-Apr-03.pdf.

3. Moore MK. Upper crossed syndrome and its relationship to cervicogenic headache. J Manipulative Physiol Ther. 2004 Jul 1;27(6):414-20.

4. Evans O, Patterson K. Predictors of neck and shoulder pain in non-secretarial computer users. Int J Ind Ergon. 2000 Sep 1;26(3):357-65.

5. Morris CE, Bonnefin D, Darville C. The Torsional Upper Crossed Syndrome: A multi-planar update to Janda's model, with a case series introduction of the midpectoral fascial lesion as an associated etiological factor. J Bodyw Mov Ther. 2015 Oct 1;19(4):681-9.

6. Ahearn I, Bird S, Gordon M. Kinesio tape's effect on musculature associated with upper cross syndrome. [Doctoral dissertation]. Chesterton, Missouri, USA: Logan College of Chiropractic. 2011 Apr 5.
7. Tunnell PW. Protocol for visual assessment: Postural evaluation of the muscular system through visual inspection. J Bodyw Mov Ther. 1996 Oct 1;1(1):21-7.

8. Hammer WI, editor. Functional soft-tissue examination and treatment by manual methods. $\quad 3^{\text {rd }}$ edition. Sudbury, Massachusetts, USA: Jones \& Bartlett Learning; 2007.

9. Christensen K. Manual muscle testing and postural imbalance. Dynamic Chiropractic. [online journal]. 2000 Nov 15;18(24). Available from: https://www.dynamicchiropractic.com/mpa cms/dc/article.php?id=31991.

10. Page P. Muscle imbalances in older adults: improving posture and decreasing pain. $\mathrm{J}$ Active Aging. 2005 Mar;4(2):30-7.

11. Kendall FP, McCreary EK, Provance PG, Rodgers MM, Romani WA. Muscles Testing and Function with Posture and Pain. 5th Edition. Baltimore, MD, USA: Lippincott Williams \& Wilkins; 2005.

12. Bernard BP, editor. Musculoskeletal disorders and workplace factors. A critical review of epidemiologic evidence for workrelated musculoskeletal disorders of the neck, upper extremity, and low back. [online document]. CDC, NIOSH, USDHHS. 1997 July. Available from: https://www.cdc.gov/niosh/docs/97141/pdfs/97-141.pdf.
13. Mubeen I, Malik S, Akhtar W, Muneeb I, Asif M, Arshad A, et al. Prevalence of upper cross syndrome among the medical students of university of Lahore. Int $\mathrm{J}$ Physiother. 2016;3(3):381-4

14. Stošić D, Milenković S, Živković D. The influence of sport on the development of postural disorders in athletes. Facta universitatis-series: Phys Edu Sport. 2011;9(4):375-84.

15. Nursyafinas, Isa KA, Intan T. A quasiexperimental study of a pilot intervention programme among UiTM dental students to curb work-related musculoskeletal disorder as an effect of performing dental extractions. Health Scope. 2019;1:441-4. Available from: https://healthscopefsk.com/index.php/resea rch/article/download/108/97/305.

16. Rajeswari SR, Rajula PB, Shankar PR, Gowda TM, Kumar TA, Mehta DS. Upper crossed syndrome and dentistry why the need for concern. Biomed J Sci Tech Res. 2017;1(7):1860-2.

17. Klussmann A, Gebhardt H, Liebers F, Rieger MA. Musculoskeletal symptoms of the upper extremities and the neck: a crosssectional study on prevalence and symptom-predicting factors at visual display terminal (VDT) workstations. BMC musculoskeletal disorders. 2008 Dec;9(1):1-6. 